DOI: 10.12731/2658-6649-2019-11-5-2-73-78

УДК 616-006.4

\title{
ПРОГРАММНОЕ ОБЕСПЕЧЕНИЕ «MINOR VARIANT FINDER» КAК ИНСТРУМЕНТ ДЛЯ АНАЛИЗА УРОВНЯ АЛЛЕЛЬНОЙ НАГРУЗКИ СОМАТИЧЕСКИМИ МУТАЦИЯМИ ПРИ ОНКОГЕМАТОЛОГИЧЕСКИХ ЗАБОЛЕВАНИЯХ
}

Маслюкова И.Е., Карнюшка А.А., Субботина Т.Н., Хазиева А.С., Дунаева Е.А., Миронов К.О.

Соматическая мутация JAK2 с.1849 G>T (V617F) приводит к цุитокин-независимому росту клеточных линий костного мозга. Она является одним из диагностических критерий хронических миелопролиферативных неоплазм. Секвенирование по Сэнгеру является золотым стандартом для анализа этой мутачии, но имеет низкую чувствительность. Программное обеспечение «Minor Variant Finder» способно обнаружить мутацию при уровне аллельной нагрузки от 5\%. Для проверки чувствительности ПО, были взяты ДНК 7-ми пациентов с ХМН с уже известнымм уровнем аллельной нагрузки. Секвенирование по Сэнгеру и анализ в «Minor Variant Finder» подтвердили заявленную чувствительность ПО.

Ключевые слова: V617F; Minor Variant Finder; хронические миелопролиферативные неоплазмы.

\section{THE SOFTWARE "MINOR VARIANT FINDER" AS A TOOL FOR ANALYZING THE LEVEL OF ALLELIC LOAD BY SOMATIC MUTATIONS IN HEMATOLOGICAL DISEASES}

\section{Maslyukova I.E., Karnyushka A.A., Subbotina T.N., Hazieva A.S., Dunaeva E.A., Mironov K.O.}

The somatic mutation of JAK2 p. 1849 G> T (V617F) leads to cytokine-independent growth of bone marrow cell lines. It is one of the diagnostic criteria for chronic myeloproliferative neoplasm. Sanger sequencing is the gold standard for analyzing this mutation, but has low sensitivity. The Minor Variant Finder software is able to detect a mutation at the level of allelic load of 5\%. To check 
the sensitivity of the software, the DNA of 7 patients with CMN with an already known level of allelic load were taken. Sanger sequencing and analysis in the Minor Variant Finder confirmed the declared sensitivity of the software.

Keywords: V617F; Minor Variant Finder; chronic myeloproliferative neoplasms.

\section{Введение}

Соматическая мутация JAK2 c.1849 G>T (V617F) приводит к увеличению активности Janus-киназы 2 и цитокин-независимому росту клеточных линий костного мозга [1]. Она является одним из диагностических критериев хронических миелопролиферативных неоплазм (ХМН). Классическими $\mathrm{Ph}$-негативными ХМН являются три заболевания: истинная полицитемия (ИП), эссенциальная тромбоцитемия (ЭТ) и первичный миелофиброз (ПМФ). У больных ИП мутация V617F выявляется в 96\% случаев, при ЭТ в $55 \%$ наблюдений и присутствует примерно в 45-68\% случаев при ПМФ [2].

Секвенирование по Сэнгеру как и прежде считается «золотым стандартом» мутационного анализа в диагностике. В тоже время, использование данного метода при онкогематологических заболеваниях связано со сложностью, как количественной оценки соматических мутаций, так и с невысокой чувствительностью, ограниченной присутствием 15-20\% мутантного аллеля. Для соматических мутаций это особенно важно, так как в отличие от герминальных мутаций, они приводят к повреждению аллелей в разной степени. Так аллельная нагрузка соматической мутацией может быть как высокой (от 50\% и выше), так и низкой (ниже 20\%). Последнее выходит за порог чувствительности секвенирования по Сэнгеру. В связи с этим требуется поиск более чувствительных молекулярных методов или специализированного программного обеспечения (ПО) для анализа соматических мутаций с низкой аллельной нагрузкой.

Компания Applied Biosystems разработала ПО «Minor Variant Finder» («MVF») для поиска малопредставленных вариантов соматических мутаций и для оценки уровня аллельной нагрузки этими мутациями. Алгоритмы ПО отфильтровывают системный шум в секвенограмме двунаправленного секвенирования. Разработчики заявляют, что ПО способно обнаружить мутацию при уровне аллельной нагрузки от 5\% [3]. «MVF» ранее не использовалось для исследования мутаций при онкогематологических заболеваниях. Но при этом соотношение аллелей с помощью данного ПО уже определялось [4].

Таким образом, перед нами стояла цель проверить заявленную чувствительность ПО «Minor Variant Finder» путем определения уровня ал- 
лельной нагрузки соматической мутацией с.1849 G>T (V617F) в гене JAK2 у пациентов с диагнозом ХМН.

\section{Материалы и методы}

Были отобраны образцы ДНК 7-ми пациентов с диагнозом ХМН и ранее выявленной мутацией с. $1849 \mathrm{G}>\mathrm{T}$. Уровень аллельной нагрузки был определен методом пиросеквенирования и находился в диапазоне от 5 до 40\%. ДНК была выделена из лейкоцитов венозной крови с помощью набора реагентов GeneJET $^{\mathrm{TM}}$ (ThermoFisherScientific). Участок гена JAK2 (377bp) амплифицировали используя праймеры JAK2_F (5'-CAAAGCACATTGTATCCTCA-3') и JAK2_R (5'-AGTCCTACAGTGTTTTCAGT-3') [5]. Продукт ПЦР очищали ExoSAP-IT. Секвенирующую ПЦР с прямого и обратного праймеров и очистку полученного продукта проводили с помощью наборов BigDyeTerminatorv3.1 и BigDyeXTerminator. Пробы подвергали капиллярному электрофорезу на генетическом анализаторе 3500 . Полученные сиквенсы сравнивали с референсной последовательностью гена JАK2 (NM_004972.3) и контролями для обоих праймеров в ПО «MVF». В качестве контроля была взята ДНК пациента без вышеуказанной мутации.

\section{Результаты}

Уровень аллельной нагрузки мутацией с.1849 G>T для выбранных образцов ДНК при использовании указанного ПО у пациента №1 составил $5,1 \%$ и $4,7 \%$; №2 - 11,0\% и $19,1 \%$; №3 - 14,1\% и $17,7 \%$; №4 - 41,2\% и $37,8 \%$; №5 - 12,0\% и 12,8\%; №6 - 13,9\% и 16,2\%; №7 - 26,4\% и $27,9 \%$ с прямого и обратного праймеров. Данный показатель при использовании пиросеквенирования составил: №1 - 5,2\% №2 - 10,5\% №3 - 20\%; №4 40\%; №5 - 20\%; №6 - 17\%; №7 - 25\% соответственно.

\section{Обсуждение}

Из 7 образцов три имели нагрузку менее $20 \%$ - образцы №1, №2 и №6. «MVF» выявило столь низкую нагрузку мутацией среди фонового шума и определило ее значение, подтверждая данные, полученные другим методом. Мутационный анализ для остальных образцов программа провела без каких-либо проблем.

В ходе работы было выяснено, что ПО подходит для анализа только однонуклеотидных замен и не может быть использовано в случае indel мутаций. «Minor Variant Finder» удобно использовать как для поиска малопредставленных вариантов, так и для определения уровня аллельной нагрузки соматической мутацией. 


\section{Выводы}

Исходя из данных, следует, что заявленная чувствительность «Minor Variant Finder» подтвердилась. То есть ПО можно использовать как дополнение к секвенированию по Сэнгеру при обнаружении однонуклеотидных замен и оценки уровня аллельной нагрузки соматической мутацией с.1849 $\mathrm{G}>\mathrm{T}(\mathrm{V} 617 \mathrm{~F})$ в 14 экзоне гена JАК2.

Информация о конфликте интересов. Авторы заявляют об отсутствии конфликта интересов.

Информация о спонсорстве. Исследование не имело спонсорской поддержки.

\section{Список литературы / References}

1. Levine R.L., Wadleigh M., Cools J. et al Activating mutation in the tyrosine kinase JAK2 in polycythemia vera, essential thrombocythemia, and myeloid metaplasia with myelofibrosis//Cancer Cell. 2005.7 (4), pp. 387-397.

2. Campbell P.J., Scott L.M., Buck G., Wheatley K., East C.L. et al Definition of subtypes of essential thrombocythaemia and relation to polycythaemia vera based on JAK2V617F mutation status: a prospective study//Lancet. 2005. 366(9501), pp.1945-1953.

3. Minor Variant Finder Software, сайт. URL: https://www.thermofisher.com/ order/catalog/product/A30835.

4. Zhuo Z., Lamont S.J., \& Abasht B. RNA-Seq Analyses Identify Frequent Allele Specific Expression and No Evidence of Genomic Imprinting in Specific Embryonic Tissues of Chicken//Scientific reports. 2017. 7(1).

5. Wu Z., Zhang Y., Zhang X., et al. A multiplex snapback primer system for the enrichment and detection of JAK2 V617F and MPL W515L/K mutations in Philadelphia-negative myeloproliferative neoplasms // Biomed Res Int. 2014.

\section{ДАННЫЕ ОБ АВТОРАХ}

Маслюкова Ирина Евгеньевна, магистрант

Федеральное государственное автономное образовательное учреждение выстего образования «Сибирский федеральный университет» пр. Свободный, 79, г. Красноярск 660041, Российская Федерация lejsmie@gmail.com

\section{Карнюшка Анастасия Александровна, магистрант} Федеральное государственное автономное образовательное учреждение высшего образования «Сибирский федеральный университет» 
пр. Свободный, 79, г. Красноярск 660041, Российская Федерация miss.anastasia-box@yandex.ru

Суббботина Татьяна Николаевна, доцент, к.б.н., зав. лаборатории Федеральное государственное автономное образовательное учреждение выстего образования "Сибирский федеральный университет»; Федеральное государственное бюджетное учреждение «Федеральныий Сибирский научно-клинический центр Федерального медико-биологического агентства»

nр. Свободный, 79, г. Красноярск 660041, Российская Федерачия; ул. Коломенская 26, г. Красноярск, 660037, Российская Федерация stn.25@mail.ru

Хазиева Анна Сергеевна, врач-гематолог

Краевое государственное бюджетное учреждение здравоохранения «Краевая клиническая больница»

ул. Партизана Железняка, 3А, г. Красноярск, 660022, Российская Федерация haas86@mail.ru

Дунаева Елена Александровна, младший научный сотрудник Федеральное бюджетное учреждение науки «Центральный научно-исследовательский институт эпидемиологии» Роспотребнадзора ул. Новогиреевская, 3а, г. Москва, 111123, Российская Федерачия ead82@mail.ru

Миронов Константин Олегович, к.м.н., старший научный сотрудник Федеральное бюджетное учреждение науки «Центральный научно-исследовательский институт эпидемиологии» Роспотребнадзора ул. Новогиреевская, 3a, г. Москва, 111123, Российская Федерачия mironov@pcr.ru

\section{DATA ABOUT THE AUTHORS}

Maslyukova Irina Evgenevna, master student

Siberian Federal University

79, Svobodny pr., Krasnoyarsk, 660041, Russian Federation

lejsmie@gmail.com

ORCID: 0000-0003-1323-2612 
Karnyushka Anastasia Aleksandrovna, master student

Siberian Federal University

79, Svobodny pr., Krasnoyarsk, 660041, Russian Federation

miss.anastasia-box@yandex.ru

ORCID: 0000-0001-7618-5177

Subbotina Tatiana Nikolaevna, docent, Candidate of biological sciences, Head of Laboratory

Siberian Federal University; Federal Siberian Research Clinical Centre under the Federal Medical Biological Agency

79, Svobodny pr., Krasnoyarsk, 660041, Russian Federation; 26, Kolomenskaya str., Krasnoyarsk, 660037, Russian Federation

stn.25@mail.ru

ORCID: 0000-0001-7790-5033

Hazieva Anna Sergeevna, hematologist

Regional Government-Owned Publicly Funded Healthcare Institution "Regional Clinical Hospital"

3A, Partizana Jeleznyaka str., Krasnoyarsk, 660022, Russian Federation haas86@mail.ru

ORCID: 0000-0001-7525-6981

Dunaeva Elena Aleksandrovna, junior researcher

Federal Budget Institution of Science "Central Research Institute of Epidemiology" of the Federal Service on Customers' Rights Protection and Human Well-being Surveillance

3a, Novogireevskaya str., Moscow, 111123, Russian Federation ead82@mail.ru

ORCID: 0000-0002-4477-8506

Mironov Konstantin Olegovich, Candidate of medical sciences, senior researcher

Federal Budget Institution of Science "Central Research Institute of Epidemiology” of the Federal Service on Customers'Rights Protection and Human Well-being Surveillance

3a, Novogireevskaya str., Moscow, 111123, Russian Federation

mironov@pcr.ru

ORCID: 0000-0001-8207-9215 